\title{
Evaluation of COVID-19 myths in Saudi Arabia
}

\author{
Noara K. Alhusseini MAS, DrPH, Muhammad R. Sajid, MD, FCPS, Haifa A. Alsheikh, Medical Student, \\ Tala H. Sriwi, Medical Student, Nour B. Odeh, Medical Student, Rawan E. Elshaer, Medical Student, \\ Rawand E. Altamimi, Medical Student, Peter M.B. Cahusac, PhD.
}

\begin{abstract}

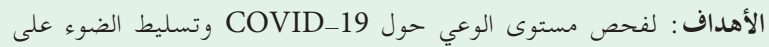

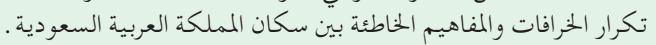

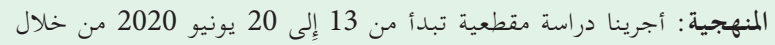

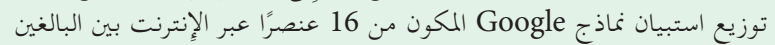

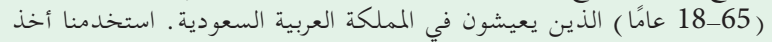

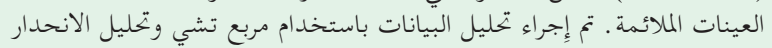

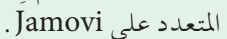

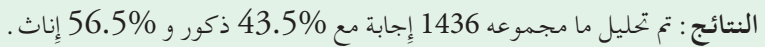

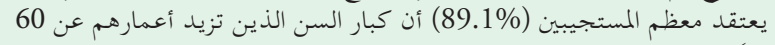

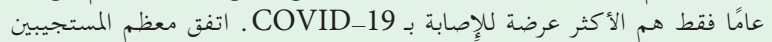

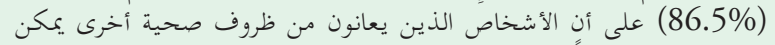
أن يكونوا أكثر تأثراً بـ

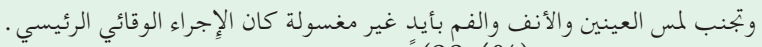

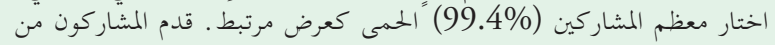

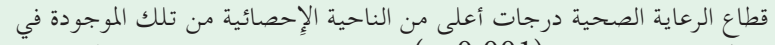

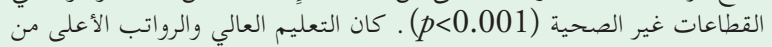

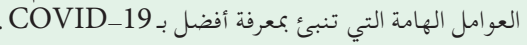

الخلاصة: يحتاج مسؤولو الصحة العامة إلى زيادة تدابير التوعية حول المرتبط بله COVID_19 المرتبط به.
\end{abstract}

Objectives: To examine the awareness level of COVID-19 and to highlight the frequency of myths and misconceptions among Saudi Arabia's population.

Methods: We conducted a cross-sectional study from June 13 to 20,2020 by distributing a 16-item online Google forms questionnaire among adults (18-65 years old) living in Saudi Arabia. We utilized the convenience sampling. Data analysis was performed using Chi-square and multiple regression analysis on Jamovi.

Results: A total of 1436 responses were analyzed with $43.5 \%$ males and $56.5 \%$ females. Most respondents (89.1\%) thought that only the elderly above 60 years old are considered at high risk of contracting COVID-19. Most respondents (86.5\%) agreed that people with other health conditions could be more affected by
COVID-19. Approximately 97.2\% agreed that wearing a mask and avoiding touching eyes, nose, and mouth with unwashed hands was the leading preventive action. Most participants (99.4\%) chose fever as an associated symptom. Respondents from the healthcare sector presented statistically higher scores than those in non-healthcare sectors $(p<0.001)$. Higher education and higher salary were important predictors of better COVID-19 knowledge.

Conclusion: Public health officials need to increase awareness measures on COVID-19 to limit myths and misconceptions and reduce psychological distress associated with it.

Keywords: COVID-19, myths, misconceptions, Saudi Arabia

Saudi Med J 2021; Vol. 42 (4): 377-383 doi: 10.15537/smj.2021.42.4.20200706

From the Department of Biostatistics and Epidemiology (Alhusseini, Cahusac); from the Department of Pathology (Sajid); from the College of Medicine (Alsheikh, Sriwi, Odeh, Elshaer, Altamimi), Alfaisal University; and from the Department of Comparative Medicine (Cahusac), King Faisal Specialist Hospital and Research Centre, Riyadh, Kingdom of Saudi Arabia.

Received 9th November 2020. Accepted 6th March 2021.

Address correspondence and reprint request to: Dr. Noara K. Alhusseini, College of Medicine, Alfaisal University, Riyadh, Kingdom of Saudi Arabia.E-mail:nalhusseini@alfaisal.edu

ORCID ID: https://orcid.org/0000-0003-4976-4194

Tn December 2019, public health officials of Wuhan 1 city (Hubei province, China) first reported cases of pneumonia of unknown causes. ${ }^{1}$ Since then, a global outbreak of severe acute respiratory syndrome (SARS) was confirmed due to infection by a novel coronavirus termed SARS-CoV-2 (COVID-19). ${ }^{2}$ On March 11, 2020, the rapid increase in the number of cases globally led the World Health Organization (WHO) to declare 
it as a pandemic. By then, 114 countries reported confirmed cases. ${ }^{3}$

Since COVID-19 is still new, peoples' initial incomprehension of the virus's impact led to underestimating strict precaution measures. Inaccurate information was readily communicated between citizens, mainly via social media platforms. Common misconceptions included believing that the virus becomes unviable at extremely high temperatures and that drinking detergents can kill the virus. ${ }^{4}$ Moreover, the myths were not limited to the nature of the virus; citizens circulated rumors on the treatment, symptoms, and transmission of COVID-19. People of all ages shared speculations on different signs and symptoms of COVID-19. Besides, people spread deceptions via social media channels on the virus's transmission by air. 5 The WHO is battling the virus and conspiracy theorists that push misinformation and undermine the pandemic's impact. $^{2}$

COVID-19 signs and symptoms vary and include fatigue, cough, fever, headache, loss of taste and smell, diarrhea, and shortness of breath. ${ }^{6}$ Contrary to popular belief, COVID-19 is not an airborne virus; rather, it is transmitted by respiratory droplets. ${ }^{7}$ Unfortunately, to date, there is no vaccination or specific drug treatment. ${ }^{8}$ Infected people are symptomatically treated and isolated until they are completely healed. Noninfected people are advised by public health officials to practice social distancing and preventative measures, including constant hand hygiene measures and wearing a mask. ${ }^{9}$

Despite the Saudi Government's measures to prevent further spread of the virus, cases remain on the rise. The Saudi Government has implemented complete lockdown and social distancing measures in public places to limit the virus' spread. ${ }^{10,11}$ Since COVID-19 is a new virus, there is limited research on awareness levels among the Saudi population. Examining the awareness level within the general population of Saudi Arabia is essential because the lack of knowledge is probably one of the leading causes of the constant rise in the number of cases.

Methods. A cross sectional study was carried out on June 13-20, 2020 among residents of Saudi Arabia. In the process of literature review, relevant keywords were used to search for prior similar researches on Google

Disclosure. Authors have no conflict of interests, and the work was not supported or funded by any drug company. scholar. We then adapted an online questionnaire from a previously pilot study validated study in the United Kingdom ${ }^{12}$ and modified it to fit the aims and scope of our study. Subsequently, an expert in the infectious diseases department at Alfaisal University, Riyadh, Saudi Arabia and an expert in the infection control department at King Faisal Specialist Hospital, Riyadh, Saudi Arabia validated the survey. Furthermore, we translated the questionnaire from English to Arabic. An Arabic version was created and handed to a faculty member at King Saud University, Riyadh, Saudi Arabia with a masters degree in linguistics to validate it for accuracy of translation.

The study included adults from 18 to 65 years of age living in Saudi Arabia. Therefore, we excluded any response that did not fit the inclusion criteria from the study. We used convenience sampling; assuming the estimated population of Saudi Arabia of 33.7 million and $95 \%$ confidence interval, we calculated a target sample size of 600. After excluding respondents under 18 and over 65 years of age, we analyzed a total of 1,439 that we received over a span of 6 days. Respondents over 65 years old were excluded due to lack of social media presence.

The questionnaire was voluntary, confidential, and anonymous-granting only principal investigators (PI) and co-PIs access to the responses. Participants indicated their age, gender, city of residence, nationality, education level, occupation, and socioeconomic status. The survey had a total of 16 closed-ended multiplechoice questions-some of which had subsections. We asked participants to answer these questions based on their perception of the virus and whether they believe the common misconceptions and myths. The questionnaire included inquiries related to causes, symptoms, transmission, precautions, treatments, infection rate, and severity of COVID-19. Therefore, this research highlights the current level of awareness and frequency of myths and misconceptions regarding COVID-19 among Saudi Arabia's population.

The ethical approval was obtained from Alfaisal University Institutional Review Board (approval number IRB20034). Researchers abided by the Saudi National Committee of Bioethics (NCBE) and the Research Policies \& Procedures of Alfaisal University. No identifying data was collected to ensure anonymity and confidentiality. The investigators only had access to the survey responses.

Statisticalanalysis. Data was extracted independently from the online survey, and no names were collected to ensure anonymity. Data was filtered manually to follow the inclusion criteria. Next, nominal and categorical data 
were entered and the statistical analysis was performed by the IBM SPSS Statistics for Windows version 20.0 (IBMCorp, Armonk, NY, USA). We initially analyzed data using Chi-square tests. We assessed the myths with the primary data points of age, gender, occupation, and socioeconomic levels. We used Chi-square test to determine statistical significance with a $p$-value of $<0.05$. Moreover, we calculated averages for each variable. We also performed multiple regression analyses for various responses.

This study's main objective is to evaluate the myths and misconceptions regarding COVID-19 among the population of Saudi Arabia.

Results. A total of 1575 responses were received from different regions in Saudi Arabia. After excluding respondents less than 18 and above 65 years of age, we analyzed 1436 responses. The socio-demographic characteristics of the respondents are depicted in Table 1.

Table 1 - Sociodemographic data of respondents.

\begin{tabular}{|c|c|c|}
\hline Variables & $\mathbf{n}$ & $\%$ \\
\hline \multicolumn{3}{|l|}{ Gender } \\
\hline Female & 812 & 56.5 \\
\hline Male & 624 & 43.5 \\
\hline \multicolumn{3}{|l|}{ Age (years) } \\
\hline $18-30$ & 770 & 53.6 \\
\hline $30-45$ & 385 & 26.8 \\
\hline$>45$ & 281 & 19.6 \\
\hline \multicolumn{3}{|l|}{ Educational level } \\
\hline Bachelor's degree & 751 & 52.3 \\
\hline High school diploma or less & 484 & 33.7 \\
\hline Master's degree or higher & 201 & 14.0 \\
\hline \multicolumn{3}{|l|}{ City } \\
\hline Riyadh & 1033 & 71.9 \\
\hline Jeddah & 167 & 11.6 \\
\hline others & 236 & 16.4 \\
\hline \multicolumn{3}{|l|}{ Nationality } \\
\hline Saudi & 1174 & 81.6 \\
\hline Non-Saudi & 265 & 18.4 \\
\hline \multicolumn{3}{|l|}{ Occupation } \\
\hline Health care provider & 461 & 32.1 \\
\hline Non-health care provider & 975 & 67.9 \\
\hline \multicolumn{3}{|l|}{ Household income (SAR) } \\
\hline$<3000$ & 68 & 4.7 \\
\hline $3000-9999$ & 195 & 13.6 \\
\hline $10000-25000$ & 351 & 24.4 \\
\hline$>25000$ & 338 & 23.5 \\
\hline Prefer not to answer & 484 & 33.7 \\
\hline
\end{tabular}

Values are presented as number and percentages (\%).
Respondents believed that the mortality rates for COVID-19 (67.6\%) and flu (67.3\%) are less than $10 \%$, and the distributions across other percentage categories were also analogous. A majority of 1289 respondents $(89.1 \%)$ thought that only the elderly population is at a higher risk of contracting COVID-19. Moreover, $86.5 \%$ of respondents agreed that people with other health conditions could be more affected by COVID-19 than their healthier counterparts, the majority answered agree $(\mathrm{n}=510,35.5 \%)$ and strongly agree $(\mathrm{n}=733,51 \%)$. Regarding vaccine availability, $1174(81.8 \%)$ stated no vaccine is currently available, $230(16.0 \%)$ did not know, and only 32 respondents $(2.2 \%)$ thought that there is a vaccine available.

Table 2 shows participants' responses regarding actions that help prevent catching an infection with COVID-19. Most participants (98.3\%) agreed that avoiding touching eyes, nose, and mouth with unwashed hands was the leading preventive action. Washing hands with soap and water for 20-30 seconds and avoiding close contact with sick people received almost identical responses with 1405 participants (97.8\%). Moreover, $97.2 \%$ agreed that wearing a mask was also an important measure. Finally, 95.8\% chose using a hand sanitizer.

Table 3 shows participants' responses regarding common signs and symptoms associated with COVID-19. Almost all participants (99.4\%) chose fever as an associated symptom. The remaining responses are in Table 3. Our next question assesses participants' responses regarding the best course of action in case they have a fever or cough and recently came into contact with someone suspected of COVID-19. The majority (837 or $58.3 \%$ ) chose to stay at home and call their primary care doctor (Table 4).

We used a score out of 11 for Q13 for the correct answers regarding knowledge regarding COVID-19. Female respondents scored slightly more than males $(p=0.412)$, Saudis showed slightly more knowledge as they scored more than non-Saudis $(p<0.265)$, respondents from the healthcare sector presented statistically higher scores than those in non-healthcare sectors $(p<.001)$, respondents with a bachelor's degree had lower scores than high school $(p=0.002)$ and master degrees $(p=0.034)$, and respondents with monthly income of 25,000 Saudi Riyals (SAR) or more scored more than their counterparts $(p<0.001)$.

For Q15, writing true or false to "Consistently wearing a face mask is highly effective in protecting you from getting infected with COVID-19," the overall correct score for males was higher than females $(p<0.019)$, and healthcare workers scored more than non-healthcare workers $(p<0.001)$. Multiple regression 
Table 2 - Responses assessing knowledge in reply to questions. Which of the following actions help prevent catching an infection with COVID-19.

\begin{tabular}{lccc}
\hline Questions & Yes & No & I do not know \\
\hline Wearing a mask & $1396(97.2)$ & $24(1.7)$ & $16(1.1)$ \\
Getting a vaccine against pneumonia & $162(11.3)$ & $620(43.2)$ & $654(45.5)$ \\
Gargling mouthwash & $299(20.8)$ & $738(51.4)$ & $399(27.8)$ \\
Washing hands with soap and water for 20-30 seconds & $1405(97.8)$ & $31(2.2)$ & $0(0)$ \\
Eating garlic & $351(24.4)$ & $603(42.0)$ & $482(33.6)$ \\
Avoiding close contact with sick people & $1403(97.7)$ & $17(1.2)$ & $16(1.1)$ \\
Taking antibiotics & $110(7.7)$ & $942(65.6)$ & $384(26.7)$ \\
Using hand sanitizer & $1376(95.8)$ & $34(2.4)$ & $26(1.8)$ \\
Putting sesame oil on skin & $16(1.1)$ & $1065(74.2)$ & $355(24.7)$ \\
Avoid touching eyes nose and mouth with unwashed hands & $1411(98.3)$ & $15(1.0)$ & $10(0.7)$ \\
Regularly rinsing nose with saline & $251(17.5)$ & $646(45.0)$ & $539(37.5)$ \\
Drinking bleach and chlorine products & $16(1.1)$ & $1317(91.7)$ & $103(7.2)$ \\
Taking prophylactic chloroquine & $73(5.1)$ & $850(59.2)$ & $513(35.7)$ \\
\hline
\end{tabular}

Values are presented as number and percentages $(\%)$.

Table 3 - Responses to the common signs and symptoms of COVID-19.

\begin{tabular}{lccc}
\hline Symptoms & Yes & No & I don't know \\
\hline Nose bleeds & $52(3.6)$ & $1019(71.0)$ & $365(25.4)$ \\
Cough & $1344(93.6)$ & $40(2.8)$ & $52(3.6)$ \\
Fever & $1428(99.4)$ & $2(0.1)$ & $6(0.4)$ \\
Skin rash & $129(9.0)$ & $908(63.2)$ & $399(27.8)$ \\
Constipation & $109(7.6)$ & $882(61.4)$ & $445(31.0)$ \\
Shortness of breath & $1415(98.5)$ & $5(0.3)$ & $16(1.1)$ \\
Frequent urination & $32(2.2)$ & $887(61.8)$ & $517(36.0)$ \\
Body aches & $1168(81.3)$ & $88(6.1)$ & $180(12.5)$ \\
\hline
\end{tabular}

Values are presented as number and percentages (\%).

analysis was conducted and showed a similar and consistent picture of these results.

We used multiple regression for score summations of Q13 (actions to avoid COVID-19 infection) and Q15 (common signs or symptoms of COVID-19). We used 6 predictors, which we expected a priori to be critical in influencing answers given to these questions. These predictors were age, nationality, gender, level of education, healthcare provider, and salary. For 2 of the predictors, level of education, and salary, there were multiple levels requiring the regression analysis to use a reference level. For level of education, this was high school diploma or less. For salary, the reference level was $<3000$ SAR. For the other binary variables, the reference levels were non-Saudi, non-healthcare provider, and male. The normality of residuals assumption was satisfied, and neither analysis exceeded a variance
Table 4 - Responses to the main ways in which people are currently getting infected with the COVID-19. Respondents could choose more than one or all options from the following options.

\begin{tabular}{|c|c|c|}
\hline Options & $\mathbf{n}$ & $\%$ \\
\hline Eating or touching bats & 243 & 16.9 \\
\hline Fecal contaminants in drinking water & 77 & 5.4 \\
\hline Unhygienic preparation of food & 210 & 14.6 \\
\hline $\begin{array}{l}\text { Sexual intercourse or sharing of needles for } \\
\text { drug use }\end{array}$ & 175 & 12.2 \\
\hline Mosquito bites & 32 & 2.2 \\
\hline $\begin{array}{l}\text { Droplets of saliva that land in the mouths } \\
\text { or noses of people who are nearby when an } \\
\text { infected person sneezes or coughs }\end{array}$ & 1338 & 93.2 \\
\hline Eating under cooked meat products & 131 & 9.1 \\
\hline $\begin{array}{l}\text { Directly coming into touch with someone's } \\
\text { bodily fluids like blood, vomit, or sweat }\end{array}$ & 494 & 34.4 \\
\hline Coming into contact with camels & 37 & 2.6 \\
\hline
\end{tabular}

inflation factor of 1.24 , thereby satisfying the lack of multicollinearity assumption.

In Q13 - Which of the following actions help prevent catching an infection with the new coronavirus (COVID-19)? Please select "True" or "False" for each option. The model, including these predictors, explained an impressive $18.9 \%$ of the variance. Omnibus ANOVA of the model predictors was all statistically significant $(p<0.05)$, except for nationality. The results from multiple regressions are shown in Table 5 .

This shows that whether the respondent was a healthcare provider or not was an important predictor, 
Table 5 - Model coefficients- Q13 overall score.

\begin{tabular}{|c|c|c|c|c|c|}
\hline Predictor & Estimate & SE & $\mathrm{t}$ & $P$-value & Stand. estimate \\
\hline Intercept & 6.6276 & 0.41239 & 16.071 & $<0.0001$ & \\
\hline \multicolumn{6}{|l|}{ Health care provider } \\
\hline $\begin{array}{l}\text { Health care provider } \\
\text { Non-healthcare provider }\end{array}$ & 1.0925 & 0.15504 & 7.047 & $<0.0001$ & 0.3909 \\
\hline Age & -0.0609 & 0.00657 & -9.261 & $<0.0001$ & -0.2730 \\
\hline \multicolumn{6}{|l|}{ Level of education } \\
\hline $\begin{array}{l}\text { Bachelor's degree } \\
\text { High school, diploma or less }\end{array}$ & 0.1080 & 0.15506 & 0.696 & 0.4864 & 0.0386 \\
\hline $\begin{array}{l}\text { Master's degree or higher } \\
\text { High school diploma or less }\end{array}$ & 0.7685 & 0.24309 & 3.161 & 0.0016 & 0.2750 \\
\hline \multicolumn{6}{|l|}{ Gender } \\
\hline $\begin{array}{l}\text { Female } \\
\text { Male }\end{array}$ & -0.2886 & 0.14016 & -2.059 & 0.0396 & -0.1033 \\
\hline \multicolumn{6}{|l|}{ Salary (Saudi Riyals) } \\
\hline I prefer not to answer & 1.1676 & 0.32794 & 3.561 & 0.0004 & 0.4177 \\
\hline 3000-9999 & 0.3466 & 0.35667 & 0.972 & 0.3314 & 0.1240 \\
\hline $10000-25000$ & 1.1474 & 0.33605 & 3.414 & 0.0007 & 0.4105 \\
\hline$>25000$ & 2.1972 & 0.33961 & 6.470 & $<0.0001$ & 0.7861 \\
\hline
\end{tabular}

in that they obtained higher scores than non-healthcare providers, with $p<0.0001$, and a large standardized estimate (last column) of 0.39 . Age was an important predictor, where younger respondents had higher scores than older, $p<0.0001$, and standardized estimate of -0.27 . Nationality was not a predictor of higher scores, $p=0.719$, and a standardized estimate of -0.02 . Level of education was an important predictor but only for Master's or higher degree $(p=0.002$ and standardized estimate of 0.27 ). Gender was a predictor, though not strong, with males achieving a higher score than females $(p=0.040)$ and standardized estimate of -0.10 . Salary was an important predictor, in that all levels of salary $>3000$ SAR had increased scores relative to the $<3000$ SAR reference level, and the higher the salary, the higher the score. The highest salaried respondents had $p<0.0001$ with an exceptionally high standardized estimate of 0.79 .

In Q15 - What are common signs or symptoms of an infection with the new coronavirus- (Covid-19)? Please select 'True or 'False' for each option. The model, including these predictors, explained less than $3 \%$ of the variance. Overall analysis using ANOVA of the predictors where only 2 of the predictors, healthcare provider and gender, were statistically significant $(p<0.05)$ regarding their knowledge on signs and symptoms.

Table 6 shows that 4 of the predictors had small standardized estimates of $<0.11$, with $p>0.05$. Whether the respondent was a healthcare provider or not was an important predictor because they obtained higher scores than non-healthcare providers, with $p<0.0001$ and a large standardized estimate of 0.30 . Gender was a marginally statistically significant predictor, with males achieving a higher score than females, $p=0.030$, and standardized estimate of -0.12 .

Discussion. Since COVID-19 is still new globally, the virus is a mystery to many public health officials, healthcare providers, and the general population. This study's main objective is to evaluate the prevalence of myths and misconceptions concerning the novel Coronavirus among the Saudi population. This evaluation will help us study the impact of the misconceptions on the daily practices of the community during the pandemic. Awareness regarding COVID-19 should be raised to control the circulation of myths and misconceptions among the Saudi population, and to help alleviate the stress associated with it. Generally, the study's findings demonstrate a good level of awareness regarding the nature of the virus and the protective factors, as less than $30 \%$ of our participants believed at least one of the following is a protective factor: gargling mouthwash, rinsing the nose with saline, and antibiotics. Unlike the study conducted in the United States and the United Kingdom. ${ }^{12}$

Wearing a mask, avoiding contact with sick people, and constant hand sanitization can prevent individuals from contracting COVID- $19 ;{ }^{13}$ our study revealed that respondents believe that wearing a mask $(97.2 \%)$ and avoiding direct contact with sick people $(97.7 \%)$ are protective measures for COVID-19. 
Table 6 - Model coefficients- Q15 overall score.

\begin{tabular}{|c|c|c|c|c|c|}
\hline Predictor & Estimate & SE & $\mathrm{t}$ & $P$-value & Stand. estimate \\
\hline Intercept & 5.7622 & 0.30043 & 19.180 & $<0.0001$ & \\
\hline \multicolumn{6}{|l|}{ Health care provider } \\
\hline $\begin{array}{l}\text { Health care provider } \\
\text { Non-healthcare provider }\end{array}$ & 0.5655 & 0.11295 & 5.006 & $<0.0001$ & 0.30398 \\
\hline Age & 0.0005 & 0.00479 & 0.105 & 0.9163 & 0.00339 \\
\hline \multicolumn{6}{|l|}{ Level of education } \\
\hline $\begin{array}{l}\text { Bachelor's degree } \\
\text { High school diploma or less }\end{array}$ & 0.1961 & 0.11296 & 1.736 & 0.0828 & 0.10540 \\
\hline $\begin{array}{l}\text { Master's degree or higher } \\
\text { High school, diploma or less }\end{array}$ & 0.1678 & 0.17709 & 0.947 & 0.3436 & 0.09019 \\
\hline \multicolumn{6}{|l|}{ Gender: } \\
\hline $\begin{array}{l}\text { Female } \\
\text { Male }\end{array}$ & -0.2229 & 0.10211 & -2.183 & 0.0292 & -0.11983 \\
\hline \multicolumn{6}{|l|}{ Salary (Saudi Riyals) } \\
\hline I prefer not to answer & -0.1070 & 0.23890 & -0.448 & 0.6544 & -0.05751 \\
\hline $3000-9999$ & 0.1392 & 0.25983 & 0.536 & 0.5922 & 0.07484 \\
\hline $10000-25000$ & 0.0874 & 0.24481 & 0.357 & 0.7210 & 0.04700 \\
\hline$>25000$ & 0.1903 & 0.24741 & 0.769 & 0.4420 & 0.10229 \\
\hline
\end{tabular}

Our findings suggest that $971(67.5 \%)$ thought the mortality rate of COVID-19 is less than $10 \%$, and $(n=966,67.1 \%)$ reported that the mortality rate for the flu is also less than $10 \%$. A cross-country study revealed that reported data is suspected to be biased by countries testing policies. However, the infection rate in all counties does not exceed $10 \%$, and that the mortality rate is at least $0.4 \% .^{14}$

Another study revealed common myths on COVID-19 on social media channels in different countries. It showed that some people believe that COVID-19 are comparable and similar. Additionally, it also revealed that a common misconception was that increasing temperatures during the summertime could kill the virus. Individuals also believed that home remedies such as drinking ginger tea and eating garlic could be protective measures and combat the virus. ${ }^{15}$ Our study findings also show that respondents stated that eating garlic (24\%), gargling mouthwash (20.8\%), regular rinsing with saline (17.5\%) prevent Covid-19 infection. However, a study shows no evidence of Covid-19 protective measures for eating garlic or rinsing with salt or saline. ${ }^{16}$

A similar study conducted, $96.3 \%$ of the US respondents and $98.3 \%$ of the UK respondents believe older adults are more likely to die from COVID-19. ${ }^{12}$ Similarly, most of our respondents, 1289 (89.1\%), thought that only the elderly above 60 years old are at high risk of contracting COVID-19. In addition, $96.3 \%$ of the US and $97.5 \%$ of the UK respondents were convinced that those with other health problems are at a higher risk of mortality due to COVID-19. ${ }^{12}$ Likewise, our study revealed that $86.5 \%$ of respondents agreed that people with other health conditions could be more affected by COVID-19 than their healthier counterparts, the majority answered agree $(n=510$, $35.5 \%)$ and strongly agree $(\mathrm{n}=733,51.0 \%)$.

Almofada et a $1{ }^{17}$ showed that males exhibited a higher level of awareness than females among the Saudi Arabian population when asked regarding the effectiveness of wearing masks in protection from COVID-19, which is consistent with our study also for $p<0.019$.

Struyf et $\mathrm{al}^{18}$ revealed that common COVID-19 signs and symptoms include cough, fever, fatigue, myalgia, and headache. Some of the symptoms are considered red flags as having a positive likelihood ratio of COVID-19. ${ }^{19}$ Our results regarding responses to the common signs and symptoms of COVID-19 included fever $(99.4 \%)$, cough $(93.6 \%)$, shortness of breath (98.5\%), and body aches $(81.3 \%)$.

A study revealed that the whole genome sequencing showed that bats are the host for COVID-19 as the homology between SRAS-COV-2 and bat Coronaviruses is $96 \%$. It also suggests that the main transmission mode is via respiratory droplets produced by the infected person. ${ }^{13}$ Our results showed that responses to the main ways of getting infected with COVID-19 were eating or touching bats (16.9\%), droplets of saliva (93.3\%) that land in the mouths or noses of people who are nearby an infected person who sneezes or coughs, and 
directly coming in touch with someone's bodily fluids like blood, vomit, or sweat (34.4\%).

Study limitations. Since the study was conducted during the lockdown, we used an online questionnaire to collect data, thereby limiting people without internet access, and affecting the generalizability of the study. Our study had many myths and misconceptions components, which adds value to the current literature, especially due to the limited studies regarding this topic in Saudi Arabia.

In conclusion, since SARS-COV2 is a novel virus, public health officials should increase awareness measures regarding COVID-19 the virus to limit myths and misconceptions and reduce psychological distress associated with it. Using educational campaigns, proper media, and social media tools is essential to control the fear of this pandemic, introduce appropriate public health safety precautions, and diminish myths and misconceptions related to COVID-19. Future studies are needed among the Saudi population to better understand their knowledge regarding COVID-19 to help in preventing and controlling this pandemic.

Acknowledgment. The authors gratefully acknowledge SCRIBENDI (www.scribendi.com) for English language editing.

\section{References}

1. Lu R, Zhao X, Li J, Niu P, Yang B, Wu H, et al. Genomic characterisation and epidemiology of 2019 novel coronavirus: implications for virus origins and receptor binding. Lancet 2020; 395: 565-574.

2. World Health Organization. Novel Coronavirus (2019-nCoV) situation report, 16-Erratum. [Updated 2020; Accessed 2021 February 4]. Available from URL: https://www.who.int/docs/ default-source/coronaviruse/situation-reports/20200205sitrep-16-ncov.pdf?sfvrsn=23af287f_4

3. World Health Organization. Coronavirus disease (COVID-19) outbreak. [Updated 2019 December 31; Accessed 2021 February 3]. Available from URL: https://www.euro.who.int/ en/health-topics/health-emergencies/coronavirus-covid-19/ novel-coronavirus-2019-ncov

4. Banerjee D, Rai M. Social isolation in Covid-19: The impact of loneliness. Int J Soc Psychiatry 2020; 55: 525-527.

5. Smith JA, Judd J. COVID-19: Vulnerability and the power of privilege in a pandemic. Heal Promot J Aust 2020; 31: 158-160.

6. Dawson P, Rabold EM, Laws RL, Conners EE, Gharpure R, Yin S, et al. Loss of taste and smell as distinguishing symptoms of coronavirus disease 2019. Clin Infect Dis 2021; 72: 682-685.
7. World Health Organization. Coronavirus disease (COVID-19): How is it transmitted? [Updated 2020 July; Accessed 2021 February 5]. Available from: https:/www.who.int/emergencies/ diseases/novel-coronavirus-2019/question-and-answers-hub/qa-detail/coronavirus-disease-covid-19-how-is-it-transmitted

8. World Health Organization. Coronavirus disease (COVID-19) [Internet]. [Updated 2020 October 12; accessed on February 5 2021]. Available from URL: https://www.who.int/emergencies/ diseases/novel-coronavirus-2019/question-and-answers-hub/qa-detail/coronavirus-disease-covid-19

9. Zhu N, Zhang D, Wang W, Li X, Yang B, Song J, et al. A Novel Coronavirus from patients with pneumonia in China, 2019. N Engl J Med 2020; 382: 727-733.

10. Algaissi AA, Alharbi NK, Hassanain M, Hashem AM. Preparedness and response to COVID-19 in Saudi Arabia: Building on MERS experience. J Infect Public Health 2020; 13: 834-838.

11. Our World in Data. Roser M, Ritchie H, Ortiz-Ospina E, Hasell J. Coronavirus Pandemic (COVID-19). 2020 Mar 4 [Updated 2021. Accessed 2021 February 5]; Available from URL: https://ourworldindata.org/coronavirus

12. Geldsetzer P. Knowledge and perceptions of COVID-19 among the general public in the United States and the United Kingdom: a cross-sectional online survey. Ann Intern Med 2020; 173: 157-160.

13. Panday DR, Panday KR, Rauniar GP. Covid-19: All facts, no myth. Kathmandu Univ Med J (KUMJ) 2020; 18: 80-89.

14. ECONSTOR. Jelnov P. Confronting Covid-19 myths: Morbidity and mortality. GLO Discussion Paper. [Updated 2020; Accessed 2021 February 5]. Available from url: https:// www.econstor.eu/handle/10419/215780

15. Singh L, Bansal S, Bode L, Budak C, Chi G, Kawintiranon K, Padden C, Vanarsdall R, Vraga E, Wang Y. A first look at COVID-19 information and misinformation sharing on Twitter. [dissetation]. Ithaca (NY): Cornell University; 2020.

16. Sahoo S, Padhy SK, Ipsita J, Mehra A, Grover S. Demystifying the myths about COVID-19 infection and its societal importance. Asian J Psychiatr 2020; 54102244.

17. Almofada SK, Alherbisch RJ, Almuhraj NA, Almeshary BN, Alrabiah B, Al Saffan A, et al. Knowledge, attitudes, and practices toward COVID-19 in a Saudi Arabian population: a cross-sectional study. Cureus 2020; 12: e8905.

18. Struyf T, Deeks JJ, Dinnes J, Takwoingi Y, Davenport C, Leeflang MMG, et al. Signs and symptoms to determine if a patient presenting in primary care or hospital outpatient settings has COVID-19 disease. Cochrane Database Syst Rev 2020; 2020: CD013665.

19. Lin CY, Broström A, Griffiths MD, Pakpour AH. Investigating mediated effects of fear of COVID-19 and COVID-19 misunderstanding in the association between problematic social media use, psychological distress, and insomnia. Internet Interv 2020; 21: 100345 . 